\title{
DIFFERENT DYNAMICS OF SENSORY-MOTOR DEVELOPMENT AND BEHAVIOR DURING THE TRANSITIONAL PERIOD IN PUPPIES: PRELIMINARY RESULTS
}

\author{
Federica Pirrone ${ }^{1}$, Ludovica Pierantoni ${ }^{2}$, Valerio Albizzati ${ }^{1}$, Mariangela Albertini ${ }^{1}$ \\ ${ }^{1}$ Department of Veterinary Medicine, University of Milan, via Celoria 10, \\ 20133 Milan, Italy \\ ${ }^{2}$ CAN (Comportamento Animale Napoli) s.s.d.r.l., Naples, Italy
}

Received 12 October 2017; Received in revised form 8 January 2018; Accepted 3 March 2018

\begin{abstract}
Many studies have analyzed the behavior of puppies during their socialization period, while little attention has been paid to the transitional period, when vision and hearing develop. Here, we compared the average age of sensory and motor development, and the behavior among a total of 25 puppies. Each litter was videotaped during 1-hour daily sessions on postnatal days 10-21 and coded for the following mutually exclusive behavioral categories: sleeping, suckling and moving. The moving category included side-to-side head swinging, exploring, rolling and allogrooming. The opening of the eyelids, appearance of the startle response and ability to stand up with either the front or hind legs were identified. The duration and frequency of puppy behaviors varied significantly with breed and season of birth. Breed and gender differences in gross motor and sensory development were also observed. These findings may turn out to be crucial to enhance the welfare, standards of rearing, and behavioral interventions aimed at improving adaptability to novel stimuli in pet dogs.
\end{abstract}

Key words: behavior, development, transitional period, puppies, dog

\section{INTRODUCTION}

Currently, there are estimated to be 77.8 million registered dogs in the US and 81 million dogs in Europe (Statista 2015). Just as humans can develop close bonds of affection with other people, so too they develop strong emotional ties with their dogs (1). For many people, the idea of family extends beyond just humans to also include pets. In fact, $93.3 \%$ of owners regard their pet as a family member, and particularly like a child $(2,3)$. Along with this comes a growing interest among dog owners and scientists in issues of canine welfare. A good start to ensuring the welfare of an animal is to focus on discreet measurable parameters, such as measures

Corresponding author: Dr. Mariangela Albertini, $\mathrm{PhD}$ E-mail address: mariangela.albertini@unimi.it

Present address: Department of Veterinary Medicine, University of

Milan, via Celoria 10, 20133 Milan, Italy

Phone: +390250318128, Fax: +390250318135

Copyright: (C) 2018 Pirrone F. This is an open-access article published under the terms of the Creative Commons Attribution License which permits unrestricted use, distribution, and reproduction in any medium, provided the original author and source are credited.

Competing Interests: The authors have declared that no competing interests exist.

Available Online First: 7 July 2018

Published on: 15 October 2018

https://doi.org/10.2478/macvetrev-2018-0018 of physiological functioning and incidence of behaviors (4). According to Plomin and Asbury (5), the combination of genetics, environment and experience during sensitive periods may affect the physiology and behavior of puppies, having neuroendocrine, behavioral or epigenetic consequences that may persist throughout life. Sensitive periods are of particular importance to canine behavior scientists and consultants, because they represent periods in development during which certain capacities are readily shaped or altered by experience. Six sensitive periods, including the prenatal period, neonatal period, transitional period, socialization period, juvenile period and adult period, in domestic canine development have been described $(6,7)$. While the socialization period, during which the puppy becomes accustomed to its own environment, has been and still is of great interest to researchers in the field of ethology (8), up to date very little research has examined the transitional period. This is a phase during which healthy puppies show a predictable pattern of rapid behavioral changes and states, sensory abilities, and physiologic 
adaptations. As their sensory organs develop, puppies begin to be bombarded by a multitude of stimuli (9) and their ability to perceive the outside world and to process information increases dramatically (10). During this period, puppies start to explore their environment and to interact with social and environmental stimuli. Consequently, the environment must provide adequate amounts, types, and timing of stimulation. Animal based research suggests that poor or little sensory exposure at this time can result in reduced sensory capacity (11) and modifications of normal patterns of postnatal sensory experience can have significant effects on early brain growth and development (12, 13). Overall, this can ultimately affect the ability of puppies to demonstrate adaptability to novel stimuli and good social skills as adults, which in turn may lead to the development of behaviors which are commonly perceived as problematic to their owners (3). Unfortunately, a large proportion of dogs are given to rescue organizations because of the owner's perception of the animal having problematic behaviors (14). It therefore becomes imperative to learn more about how and when exactly the behavioral and sensory systems become functional in postnatal development and to explore the potential benefits of addressing these notions to promote successful puppy breeding, rearing and ownership.

The transitional period is typically designated as beginning with the opening of the eyelids and ending when the startle response appears (10). It is worth reminding that the various sensory systems do not become functional at the same time in prenatal and postnatal development, and this asynchronous activation likely has significant consequences for the course of early postnatal perceptual development (15). Moreover, much remains to be learned about links between the order and timing of early sensory experience and postnatal perceptual processing (16).
Developmentally, with growth the sensory acuity increases, the muscles become stronger and more functional, and the central nervous system matures. All these improvements cause the motor responses to become better organized and behaviors being even more complex and under voluntary control. Vice versa, increased behavioral activity stimulates the development of new synapses, thus strengthening neural pathways (17).

The present study addressed this issue by analyzing the three behavioral categories (sleeping, suckling, moving) that are reliably recognized in puppies during the transitional period, as well as their sensory-motor development. The objective was to explore these patterns and to examine whether and how they differed by breed, gender, litter size and season of birth of puppies.

\section{MATERIAL AND METHODS}

\section{Animals}

Observations of puppies were conducted on 5 different litters with no kinship (2 of Jack Russell terriers and 3 of Beagles), through continuous video recordings on postnatal days 10 to 21 . All of the dogs in this study (a total of 25 pups: 13 males and 12 females) were from the same official breeder, that complies with the Dog Breeder Code of Ethics provided by the Italian Kennel Club E.N.C.I. (18), which establishes both standards and guidelines for the ownership, breeding, and sales of the dogs. Main characteristics of litter data are reported in Table 1.

The females were all multiparous and between 2 and 8 years old (average $5.2 \pm 1.2$ SEM), and the litter sizes varied from 2 to 7 (average $5 \pm 0.9$ SEM). The puppies were all conceived naturally and were born by natural birth. Females stayed with their pups in fostering rooms which included both an indoor whelping area $(2 \times 1.5 \mathrm{~m})$ and an outdoor

Table 1. Main characteristics of litter data according to breeds, sex and season of birth

\begin{tabular}{cccc}
\hline Number & Breed & Sex & Season \\
\hline 4 & Beagle & male & spring \\
4 & Beagle & female & spring \\
4 & Beagle & female & summer \\
4 & Jack Russell terrier & male & spring \\
3 & Jack Russell terrier & female & spring \\
5 & Jack Russel terrier & male & summer \\
1 & Jack Russel terrier & female & summer \\
\hline
\end{tabular}


space $(4 \times 2 \mathrm{~m})$, until puppies were weaned at the age of eight weeks. The outdoor environment was adequately protected against bad weather and direct sunlight. All the puppies were gently handled daily, as this practice has been shown to have beneficial effects on the emotional development and welfare of the puppy $(19,20)$.

\section{Observation and recording procedure of puppies}

Behavior was recorded continuously for all litters by an experimenter with a digital camera, and video files were stored for later analysis offline. Behavioral recordings were done using animal focal sampling during 1-hour daily sessions in the morning (10:00 a.m.), while the pups were mainly confined to the pup box. This observation schedule provided $12 \mathrm{~h}$ of continuous recordings per litter. Analysis of behavior was carried out using the Observer XT software package (Noldus Information Technology, 6702 EA Wageningen, The Netherlands). We identified three mutually exclusive behavioral categories, namely sleeping, suckling and moving (Table 2). The behaviors of each single puppy were analyzed in terms of relative frequency (rate per minute) and duration. The age of onset of eyelid opening, startle response to auditory stimuli and puppy's ability to support its weight on either the forelimbs or all four legs were measured. Startle tests were conducted by startling the pups with a handclap. A positive response was marked by a sudden abduction of the limbs, flexion on the head and blinking of the eyes after startling (21). After the startle event, the experimenter handled the puppy gently, with petting and soothing voice. In order to avoid interference with the behavioral observations, the test was always performed at the end of the 1-hour recording session.

Intra-observer reliability of the experimenter who analyzed the videos was computed by coding of independent samples of videotaped sessions twice several weeks apart and calculating the percentage of agreement (22), which revealed a kappa value of 0.85 (95\% CI: 0.81-0.92).

\section{Statistical analysis}

Statistical analysis was performed using IBM SPSS Statistics for Windows, version 24.0 (IBM Corp, Armonk, NY). All data were analyzed through nonparametric statistical tests. The Kruskal-Wallis test for multiple comparisons and the Mann-Whitney U-test with the Bonferroni correction for pairwaise comparisons were used to analyze sex, breed and season of birth differences in the duration of behaviors, as well as age at onset of sensory-motor development. Pearson $\chi^{2}$ test of independence was applied in $2 \times 2$ contingency tables to compare breed differences in the prevalence of behaviors. Values are expressed as the mean \pm SEM. $P$ values $\leq 0.05$ and $\leq 0.01$ were deemed statistically significant and highly significant, respectively.

\section{RESULTS}

\section{Sensory-motor development}

Table 3 shows the mean age at which puppies exhibited eyelid unsealing, onset of auditory function and ability of getting up on either the front or hind legs. On average, puppies opened their eyes and started getting up on front legs 12 days after birth, whereas they started getting up on hind legs and startled to noise 17 to 18 days after birth.

Nonparametric Mann-Whitney U comparisons revealed a pattern of within-breed effects on timing of sense and motor skill development (Fig.1). In particular, Beagles could be distinguished by earlier onset of the acoustic reflex and delayed motor skill development compared to Jack Russel terriers.

Table 2. Behavioral variables recorded during the study

\begin{tabular}{lll}
\hline Category & Behaviors & Description \\
\hline Sleeping & - & lying either in lateral, sternal or dorsal recumbency; eyes are closed \\
\hline Suckling & - & nipple grasping accompanied by forelimb thrusting \\
\hline Moving: & side-to-side head swinging & swinging the head from side to side, occasionally moving the front legs \\
\hline & exploring & moving slowly, apparently sniffing or mouthing/ sniffing the environment \\
\cline { 2 - 3 } & rolling around & rolling around on the floor \\
\cline { 2 - 3 } & allogrooming & two or more individuals interacting, especially licking the anogenital region \\
\cline { 2 - 3 }
\end{tabular}




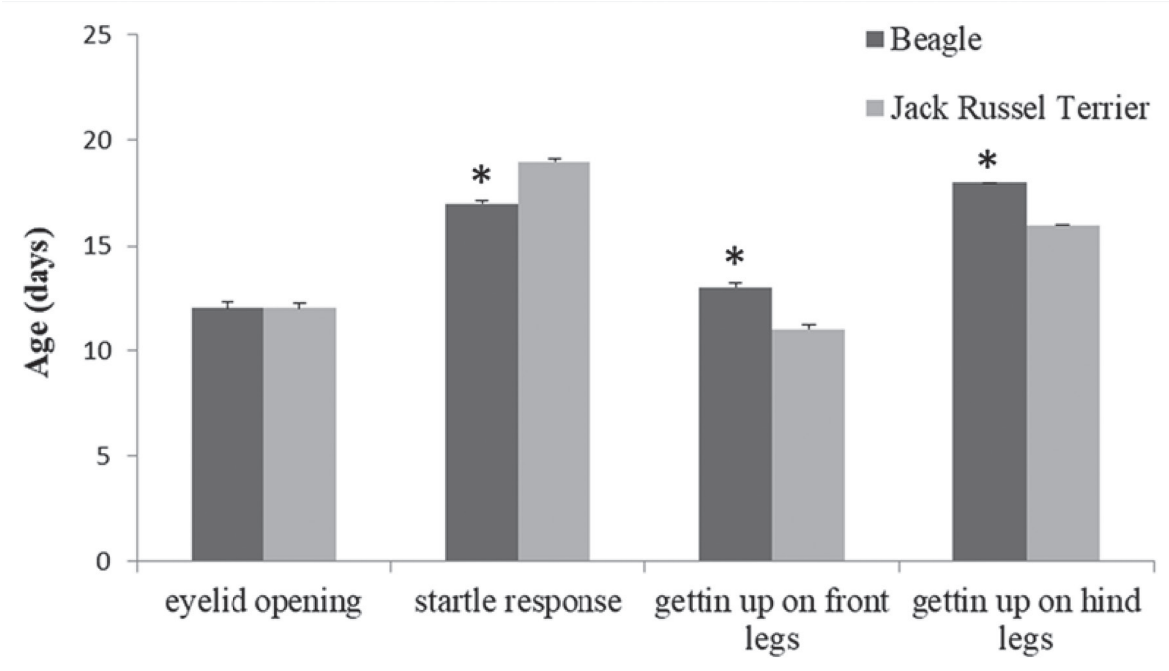

Figure 1. Breed differences in mean age at onset of sensory-motor development

Values are means \pm SEM. ${ }^{*}, \mathrm{P} \leq 0.05$

In Beagles, but not in Jack Russel terriers, from the day of occurrence of the acoustic reflex onward moving bouts became significantly $(\mathrm{P}=0.001)$ longer $(347.82 \pm 43.70 \mathrm{sec})$ compared to previous days $(184.33 \pm 16.67 \mathrm{sec})$. A significant sexdifference in the mean age of eye opening was found: females had their onset earlier than males (11.37 \pm 0.28 days versus $12.64 \pm 0.14$ days, $\mathrm{P}=0.026$ ). No significant effect was found for litter size.

\section{Behaviors}

Nonparametric within-breed comparisons revealed that Jack Russel terriers displayed longer suckling $(295.11 \pm 15.7 \mathrm{sec})$ and more frequent sleeping bouts ( $0.2 \pm 0.0$ acts per minute) than did Beagle puppies (suckling: $219.6 \pm 16.0 \mathrm{sec}, \mathrm{P}=0.001$; sleeping bouts $0.11 \pm 0.0$ acts per minute, $\mathrm{P}=0.048$ ) (Fig. 2, 3). Moreover, Jack Russel terriers displayed sleeping episodes immediately after suckling $(50.3 \%)$ significantly more frequently than Beagles $(40 \%)\left(\chi^{2}=6.325\right.$ on $\left.1 \mathrm{df}, \mathrm{P}=0.012\right)$. In other words,
Jack Russel terriers seemed to be relaxed, slow feeders; they did nurse more than Beagles, falling asleep frequently.

Beagles were more active than Jack Russel terriers, as they spent more time moving (239.53 $\pm 14.91 \mathrm{sec} v s 135.66 \pm 22.84 \mathrm{sec}, \mathrm{P}=0.003)$ and all moving behaviors were also significantly more frequent than in Jack Russel terriers (Table 4).

The variable "season" had a statistically significant effect on suckling, sleeping and moving. Puppies born in spring had longer suckling bouts than those born in summer $(366.00 \pm 19.36 \mathrm{sec} v s$ $262.99 \pm 17.64 \mathrm{sec}, \mathrm{P}=0.012$ ). They also had longer $(939.84 \pm 29.31 \mathrm{sec}$ vs $872.31 \pm 23.16 \mathrm{sec}, \mathrm{P}=0.040)$ but less frequent sleeping episodes $(0.094 \pm 0.00 \mathrm{act} /$ $\min$ vs $0.129 \pm 0.00 \mathrm{act} / \mathrm{min}, \mathrm{P}=0.002)$. Moreover, spring puppies spent longer periods moving than summer puppies $(219.00 \pm 15.70$ vs $128.47 \pm 26.67$, $\mathrm{P}=0.003)$, though again less frequently $(0.083 \pm$ $0.004 \mathrm{act} / \mathrm{min} v s 0.102 \pm 0.008 \mathrm{act} / \mathrm{min}, \mathrm{P}=0.003$ ).

Table 3. Mean age of sensory-motor development

\begin{tabular}{lcc}
\hline Senses and mobility & \multicolumn{2}{c}{ Age (days) } \\
\hline Eyelid opening & Mean \pm SEM & Minimum - Maximum \\
\hline Startle response & $12.12 \pm 0.18$ & $10-13$ \\
\hline Getting up on front legs & $18.70 \pm 0.18$ & $17-20$ \\
\hline Getting up on hind legs & $12.20 \pm 0.25$ & $10-14$ \\
\hline SEM, standard error of the mean & $17.16 \pm 0.18$ & $15-19$ \\
\hline
\end{tabular}




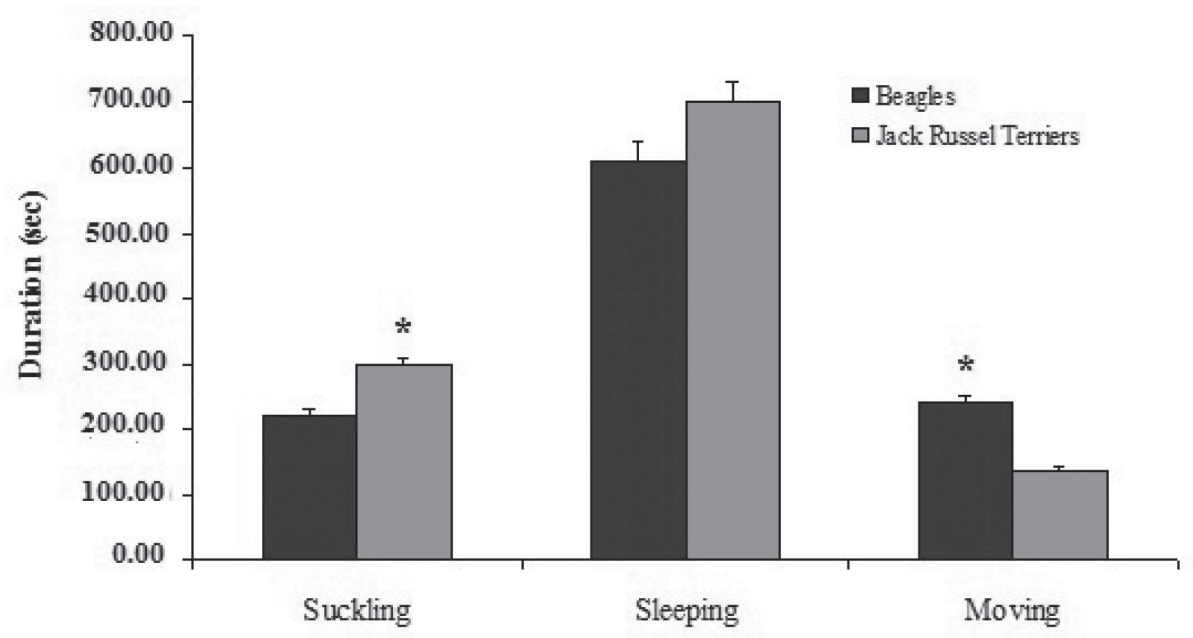

Figure 2. Breed differences in the time spent by all the puppies, expressed in seconds, in the three behavioral categories. Mann-Whitney U-test with the Bonferroni correction used $(\mathrm{P} \leq 0.001)$

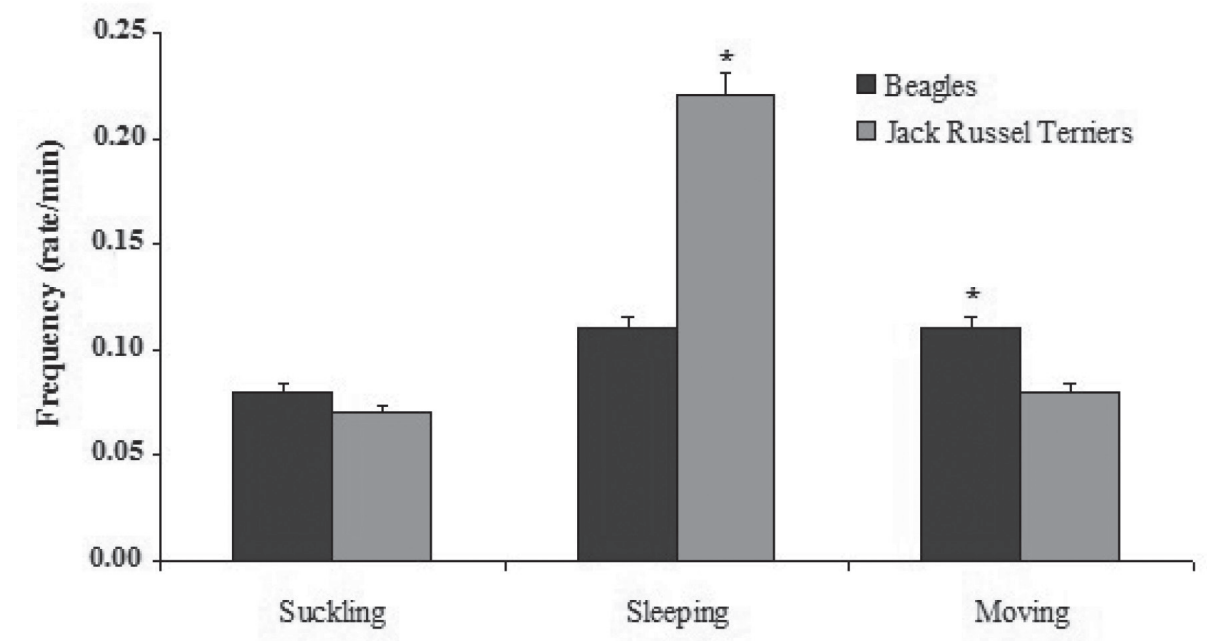

Figure 3. Breed differences in mean frequency of behaviors. Mann-Whitney U-test with the Bonferroni correction used $(\mathrm{P} \leq 0.001)$

Table 4. Breed differences in mean relative frequency (rate per minute) of moving behaviors

\begin{tabular}{|c|c|c|c|c|c|}
\hline \multirow[t]{2}{*}{ Moving Behaviors } & \multirow[t]{2}{*}{ Breed } & \multicolumn{2}{|c|}{ Rate per minute } & \multirow[t]{2}{*}{ Mann-Whitney } & \multirow[t]{2}{*}{ U-test P (two-sided) } \\
\hline & & Mean & SEM & & \\
\hline \multirow{2}{*}{ Exploring } & Beagle & 0.11 & 0.0 & \multirow{2}{*}{\multicolumn{2}{|c|}{0.001}} \\
\hline & Jack Russel Terrier & 0.06 & 0.0 & & \\
\hline \multirow{2}{*}{ Side-to-side head swinging } & Beagle & 0.10 & 0.0 & \multirow{2}{*}{\multicolumn{2}{|c|}{0.001}} \\
\hline & Jack Russel Terrier & 0.08 & 0.0 & & \\
\hline \multirow{2}{*}{ Grooming } & Beagle & 0.08 & 0.0 & \multirow{2}{*}{\multicolumn{2}{|c|}{0.012}} \\
\hline & Jack Russel Terrier & 0.06 & 0.0 & & \\
\hline \multirow{2}{*}{ Rolling around } & Beagle & 0.08 & 0.0 & \multirow{2}{*}{\multicolumn{2}{|c|}{0.001}} \\
\hline & Jack Russel Terrier & 0.04 & 0.0 & & \\
\hline
\end{tabular}

SEM, standard error of the mean. 


\section{DISCUSSION}

We investigated the puppy's perceptual and motor development and behavior during the transitional period, and whether there were significant differences between sexes, breeds and spring versus summer-born puppies. In the current study, based on the mean age at which puppies' eyes unsealed and the startle reflex occurred, the time range was 12-19 days, which is quite in line with what other investigators have reported $(9 ; 10$; 23; 24). However, the pups showed significantly different timings and patterns. Opening of the eyes occurred significantly earlier in females than in males. Sex differences have been reported in several facets of infant vision, with girls preceding boys in the maturation of visual acuity (25), and evoked responses to changes in the visual pattern (26). It should be noticed, however, that these early sex differences in maturation of visual processes are transient and appear to have no long-term consequences for behavior (27).

In light of the critical role played by the timing of early postnatal sensory development in guiding and shaping perception, learning and memory (28; 29), these findings underscore the need for additional multi-breed studies including larger number of puppies. The acoustic reflex response appeared significantly earlier in Beagles than in Jack Russel terriers.

It is worth clarifying that the onset of acoustic reflex does not exactly coincide with the beginning of a puppy's auditory ability, that could only be highlighted using sophisticated survey methods (e.g., functional magnetic resonance imaging) (30), but with a puppy's capacity to demonstrate it. The acoustic startle reflex is a contraction of muscles in response to a sound of high intensity which is commonly used to measure the behavioral response to sound in animals (31), and, in turn, may be used to indirectly estimate hearing sensitivity.

The auditory startle reflex has a well-known adaptive function, as it prepares the organism for situation of alert in relation to unexpected events, and is therefore responsible for protecting the individual. Recently, some studies have found couplings between human infant auditory function and the developmental processes of body movements $(32,33)$, particularly those sociallyoriented communicative, thus pinpointing the evolutionary importance of auditory-motor interactions for development of social interactions (34). It is likely that coupling between acoustics and these movements, integrated as early as at the beginning of postnatal life, help motivate environment interaction (34). The behavioral dynamics of Beagle puppies in our study could be seen from this perspective. In fact, Beagle puppies stayed awake for longer and more frequent intervals, during which they were more explorative (e.g., exploring behavior with the head and eyes) and socially interactive with their littermates (e.g., social grooming), and these periods increased significantly precisely following the onset of auditory function. These findings suggest that movement might play a role in facilitating the maturational course of acoustic sensory. However, this potential causal relationship deserves more detailed investigation.

Moreover, in human newborns, higher neonatal activity level is positively associated with higher approach to novelty (35) in early childhood. Whether puppies' higher activity level might meaningfully predict their later temperament is also worth investigating further.

Jack Russel terriers, in turn, had earlier gross motor development of the type associated with myelination of motor neurons, which milestones were considered here in terms of starting to stand up on the four limbs. The standing posture drives the developmental transition from crawling to walking, carrying multiple benefits to the puppy. Standing up constrains looking in other ways. As for infants, while prone or crawling, puppies mostly see the floor; but when they sit or stand up, the whole room swoops into view (36). Standing is the prelude to walking, by which puppies may cover more space more quickly, and what they gain in space and speed has implications for exploration and engagement with the surrounding environment (37). Lastly, walking provides puppies with new opportunities for actions and interactions in their social context. All in all, postural skill acquisition is important because it serves as a foundation for the development of functional skills in early life (38), being a strategy that will facilitate developmental change in perceptual, cognitive, and social domains too (39). Childrearing practices have a profound influence on which motor skills children acquire, the age and sequence in which children acquire them, and the subsequent developmental trajectory (39). The influence should be similar in puppy dogs and deserves deeper investigation.

Jack Russel terriers exhibited a peculiar regulation of nursing, with long suckling bouts coupled with frequent sleeping. A similar infantregulated pattern has been previously observed 
by Dienske Van Vreeswijk (40) in chimpanzees, in which longer nursing was followed by relatively long pauses with daytime sleep. As suckling fulfils a combination of nutritional and social (comfortrelated) needs, this would suggest a higher dependency upon their mother in Jack Russel terriers, compared to Beagles.

The behavioral analysis showed that, in all puppies, the suckling duration and frequency was affected by the season of birth, and so this factor would need to be taken into account in assessments of neonate puppies. In fact, the longer suckling bouts as well as the longer and less frequent sleeping episodes during spring may indicate that puppies were not bothered by the excessive heat of the summer days, when the ambient temperatures have reached higher values.

In conclusion, the transitional period represents a radical change in the newborn puppy's living conditions and physiological functions, because it is when the puppy begins to perceive a wide array of stimuli from which give sense of the surrounding world. We found either breed, sex or season of birth-dependent differences in the sensory-motor and behavioral timing and dynamics of puppies which could affect their later processes of learning and development. Moreover, we provided potential evidence of how early movements might accelerate sensory maturation in puppies, probably by their direct effect on sensory stimulation.

This pilot study is the initial step in our research to examine the puppy's early development and its contribution to later behavior and ability to adapt to novel stimuli, which is of relevance for appropriate puppy breeding and rearing practices, as well as for successful ownership.

\section{CONFLICT OF INTEREST STATEMENT}

The authors declared that they have no potential conflict of interest with respect to the authorship and/or publication of this article.

\section{ACKNOWLEDGMENT}

We thank Paolo Petrucci and the Training and Breeding Center Bau House, Via Mera 13, 20900 Monza (MB) - Italia, for making this study possible.

\section{REFERENCES}

1. Virués-Ortega, J., Buela-Casal, G. (2006). Psychophysiological effects of human-animal interaction: theoretical issues and long-term interaction effects. J Nerv Ment Dis. 194 (1): 52-57. https://doi.org/10.1097/01.nmd.0000195354.03653.63 PMid:16462556

2. Kubinyi, E., Turcsán, B., Miklósi, Á. (2009). Dog and owner demographic characteristics and dog personality trait associations. Behav Processes. 81(3): 392-401.

https://doi.org/10.1016/j.beproc.2009.04.004

PMid:19520239

3. Pirrone, F., Pierantoni, L., Mazzola, S.M., Vigo, D., Albertini, M. (2015). Owner and animal factors predict incidence of, and owner reaction towards, problem behaviors in companion dogs. J Vet Behav: Clin Appl Res. 10, 295-301.

https://doi.org/10.1016/j.jveb.2015.03.004

4. Marchant-Forde, J.N. (2015). The science of animal behavior and welfare: challenges, opportunities, and global perspective. Front Vet Sci. 2, 16. https://doi.org/10.3389/fvets.2015.00016 PMid:26664945 PMCid:PMC4672293

5. Plomin, R., Asbury, K. (2005). Nature and nurture: Genetic and environmental influences on behaviour. Ann Am Acad Pol Soc Sci. 600, 86-98. https://doi.org/10.1177/0002716205277184

6. Overall, K.L. (2013). Canine behavior. Normal canine behavior and ontogeny: neurological and social development, signaling and normal canine behaviors. In: Elsevier (Ed.), Manual of clinical behavioral medicine for dogs and cats. First Ed. (pp. 123-128). Mosby Year Book, Inc., St. Louis, Missouri.

7. Scott, J., Fuller, J. (1965). Genetics and the social behavior of the dog. University of Chicago Press, Chicago, IL.

8. Uzunova, K., Stoyanchev, K., Semerdzhiev, V., Rusenov, A., Penchev, I., Kostov, D. (2007). Study on the behaviour of puppies with regard to their socialization. Trakia J Sci. 5(3-4): 12-15.

9. Houpt, K.A. (2011). Development of Behavior. In: Blackwell Publishing (Ed.), Domestic animal behavior for veterinarians and animal scientists. Fifth Edition. (p. 416). John Wiley \& Sons, New York.

10. Case, L.P. (2013). Developmental Behavior: Puppy to Adult. In: Blackwell Publishing (Ed.), The dog: Its behavior, nutrition, and healt. Second Edition. Chapter 7. Iowa State University Press. 
11. Bateson, P. (1979). How do sensitive periods arise and what are they for? Anim Behav 27, 470-486. https://doi.org/10.1016/0003-3472(79)90184-2

12. King, A.J., Carlile, S. (1993). Changes induced in the representation of auditory space in the superior colliculus by rearing ferrets with binocular eyelid suture. Exp Brain Res. 94, 444-455.

https://doi.org/10.1007/BF00230202

PMid:8359258

13. Wallace, M.T., Stein, B.E. (2007). Early experience determines how the senses will interact. J Neurophysiol. 97, 921-926.

https://doi.org/10.1152/jn.00497.2006

PMid:16914616

14. Blackwell, E.J., Casey, R.A., Bradshaw J.W.S. (2003). The assessment of shelter dogs to predict separation-related behaviour and the validation of advice to reduce its incidence post-homing. (p. 4). Horsham, UK: RSPCA.

15. Lickliter, R. (2005). Prenatal sensory ecology and experience: Implications for perceptual and behavioral development in precocial birds. Adv Study Behav. 35, 235-274.

https://doi.org/10.1016/S0065-3454(05)35006-6

16. Lickliter, R. (2011). The integrated development of sensory organization. Clin Perinatol. 38(4): 591-603. https://doi.org/10.1016/j.clp.2011.08.007 PMid:22107892 PMCid:PMC3223372

17. Garland, E., Howard, M.O. (2009). Neuroplasticity, Psychosocial genomics, and the biopsychosocial paradigm in the 21 st century. Health \& Social Work. 34(3): 191-199.

https://doi.org/10.1093/hsw/34.3.191

PMid:19728478 PMCid:PMC2933650

18. E.N.C.I., the Italian Kennel Club. (2015). The dog breeder code of ethics. Available at: http://www. enci.it/media/2115/f-7249_01.pdf. Accessed October 29, 2015.

19. Battaglia, C.L. (2009). Periods of early development and the effects of stimulation and social experiences in the canine. J Vet Behav: Clin Appl Res. 4(5): 203210 .

https://doi.org/10.1016/j.jveb.2009.03.003

20. Gazzano, A., Mariti, C., Notari, L., Sighieri, C., McBride, E.A. (2008). Effects of early gentling and early environment on emotional development of puppies. Appl Anim Behav Sci. 110, 294-304. https://doi.org/10.1016/j.applanim.2007.05.007

21. Fox, M.W. (1968). Methods of animal experimentation. III (2):37-73. Elsevier Inc.
22. Landis, J.R., Koch, G.G. (1975). A review of statistical methods in the analysis of data arising from observer reliability studies (Part II). Stat Neerlandica 29(4):151-161.

https://doi.org/10.1111/j.1467-9574.1975.tb00259.x

23. Scott, J.P. (1958). Critical periods in the development of social behavior in puppies. Psychosom Med XX (1): 1-13.

https://doi.org/10.1097/00006842-195801000-00005

24. Luescher, U.A. (2012). Canine behavioral development. Based on a chapter published in Peterson, ME, Kutzler MA (eds): Small Animal Pediatrics. St. Louis, 2011, Elsevier.

25. Makrides, M., Neumann, M.A., Gibson, R.A. (2001). Perinatal characteristics may influence the outcome of visual acuity. Lipids 36 (9): 897-900. https://doi.org/10.1007/s11745-001-0799-0 PMid:11724461

26. Malcolm, C., McCulloch, D.L., Shepherd, A. (2002). Pattern-reversal visual evoked potentials in infants: gender differences during early visual maturation. Dev Med and Child Neurol. 44 (5): 345-351. https://doi.org/10.1111/j.1469-8749.2002.tb00822.x PMid:12033721

27. Alexander, G.M., Wilcox, T. (2012). Sex differences in early infancy. Child Dev Perspect. 6 (4): 400-406. https://doi.org/10.1111/j.1750-8606.2012.00247.x

28. Lickliter, R., Bahrick, L.E., Markham, R.G. (2006). Intersensory redundancy educates selective attention in bobwhite quail embryos. Dev Sci. 9(6): 604-615.

https://doi.org/10.1111/j.1467-7687.2006.00539.x PMid:17059458 PMCid:PMC1813927

29. Lickliter, R., Bahrick, L.E., Honeycutt, H. (2004). Intersensory redundancy enhances memory in bobwhite quail embryos. Infancy 5(3): 253-69. https://doi.org/10.1207/s15327078in0503_1

30. Bach, J., Lüpke, M., Dziallas, P., Wefstaedt, P., Uppenkamp, S., Seifert, H., Nolte, I. (2016). Auditory functional magnetic resonance imaging in dogs - normalization and group analysis and the processing of pitch in the canine auditory pathways. BMC Vet Res. 12, 32.

https://doi.org/10.1186/s12917-016-0660-5 PMid:26897016 PMCid:PMC4761139

31. Hansen, A., Wei, S. (2014). Acoustic startle response affected by aging and cholinergic neurotransmitters. J Otol. 9(2): 73-80. https://doi.org/10.1016/S1672-2930(14)50018-9

32. Phillips-Silver, J., Trainor, L.J. (2007). Hearing what the body feels: auditory encoding of rhythmic movement. Cognition 105(3): 533-546. https://doi.org/10.1016/j.cognition.2006.11.006 PMid:17196580 
33. Ejiri, K., Masataka, N. (2001). Co-occurrence of preverbal vocal behavior and motor action in early infancy. Dev Sci. 4, 40-48.

https://doi.org/10.1111/1467-7687.00147

34. Ferronato, P.A.M., Domellöf, E., Rönnqvist, L. (2014). Early influence of auditory stimuli on upper-limb movements in young human infants: an overview. Front Psychol. 5, 1043.

https://doi.org/10.3389/fpsyg.2014.01043

PMid:25278927 PMCid:PMC4166959

35. Korner, A., Zeanah, C., Linden, J., Berkowitz, R., Kramer, H., Agras, W. (1985). The relationship between neonatal and later activity and temperament. Child Dev. 56, 38-42.

https://doi.org/10.2307/1130171

PMid:4039245

36. Kretch, K.S., Franchak, J.M., Adolph, K.E. (2014). Crawling and walking infants see the world differently. Child Dev. 85(4): 1503-1518.

https://doi.org/10.1111/cdev.12206

PMid:24341362 PMCid:PMC4059790

37. Adolph, K.E., Tamis-LeMonda, C.S. (2014). The costs and benefits of development: the transition from crawling to walking. Child Dev Perspect. 8(4): 187-192.

https://doi.org/10.1111/cdep.12085

PMid:25774213 PMCid:PMC4357016
38. Dusing, S.C., Harbourne, R.T. (2010). Variability in postural control during infancy: implications for development, assessment, and intervention. Phys Ther. 90(12): 1838-1849.

https://doi.org/10.2522/ptj.2010033

PMid:20966208 PMCid:PMC2996511

39. Adolph, K.E., Robinson, S.R. (2015). Motor development. In: L. S. Liben, U. Mueller, \& R. M. Lerner (Eds.), Handbook of child psychology and developmental science, Volume 2, Cognitive processes (pp.113-157). John Wiley \& Sons, New York.

https://doi.org/10.1002/9781118963418.childpsy204

40. Dienske, H., Van Vreeswijk, W. (1987). Regulation of nursing in chimpanzees. Dev Psychobiol. 20(1): 71-83.

https://doi.org/10.1002/dev.420200110

PMid:3556786

Please cite this article as: Pirrone F., Pierantoni L., Albizzati V., Albertini M. Different dynamics of sensory-motor development and behavior during the transitional period in puppies: preliminary results. Mac Vet Rev 2018; 41 (2): $153-161$.

https://doi.org/10.2478/macvetrev-2018-0018 